\title{
Bungendore health impact assessment: urban development in a rural setting
}

\author{
Andrew J. Gow ${ }^{\mathrm{A}, \mathrm{B}}$ and Lorraine G. Dubois ${ }^{\mathrm{A}}$ \\ ${ }^{A}$ Health Development, Greater Southern Area Health Service \\ ${ }^{\mathrm{B}}$ Corresponding author. Email: \\ andrew.gow@gsahs.health.nsw.gov.au
}

\begin{abstract}
As the majority of the determinants of health are controlled outside the health system, the challenge for promoting health is to find a way of influencing these determinants. Health impact assessment was used in Bungendore, NSW, in an attempt to influence decisions relating to scenarios for urban development. Twelve months after the project was completed, interim evaluation has revealed evidence that the health impact assessment has had a positive effect on preliminary landuse planning work.
\end{abstract}

There is considerable evidence that health is a product of more than just biology and personal choices of lifestyle. A range of other factors including social determinants and the built environment are regarded as creating the context in which health is either enhanced or diminished. ${ }^{1,2}$ The challenge, however, lies in the fact that the majority of the determinants of health are outside the direct control of the health system. Health impact assessment (HIA) is one methodology that has been posited as having the potential to add concepts of health to the agenda of non-health agencies, particularly in the context of land-use planning. ${ }^{1,2}$

\section{Process}

Greater Southern Area Health Service has established relationships with various local government areas to address health promotion priorities, largely through social planning processes. ${ }^{3}$ Collaboration using HIA was seen as having the potential to extend such relationships. The Bungendore HIA was established as part of the NSW Health Impact Assessment Project. The project was one of five developmental sites established to further explore use of the HIA methodology. 4

Bungendore is a small NSW town of approximately 2000 people $35 \mathrm{~km}$ east of Canberra within the Palerang Local Government Area. The Bungendore HIA examined the potential health effects of two possible residential developments for Bungendore. The first scenario considered Infill Development within the existing village boundaries of Bungendore, for the next 10 to 15 years, until available land supplies have been exhausted. The second scenario was a combination of Infill Development and Greenfield Development (where adjoining agricultural land is rezoned for residential purposes). ${ }^{5}$

The HIA was conducted following the six steps described by Simpson. ${ }^{6}$ The analysis considered the impact on physical activity, water and good neighbourliness. Neither development scenario was found to be preferable to the other in terms of potential health impacts. Instead, several health-promoting elements were identified for incorporation into the Palerang Local Environmental and Social and Community Plans (Table 1).

\section{Evaluation}

Twelve months after completing the HIA, a process and interim impact evaluation was undertaken. ${ }^{7}$ The evaluation updated and reported on the outputs of the HIA with a view to a further evaluation in 2008 . The process evaluation was a document analysis focussing on the processes involved in conducting the HIA, including comparison between initial project plan, screening report, scoping report and actual project progress. The evaluation was guided by the question: was the project implemented as intended $?^{8-11}$

Overall, the document analysis confirmed that the project was implemented as intended, including the use of a rapid HIA methodology. It also identified that: (i) the use of a project agreement with identified responsibilities assisted in keeping the project on track; and (ii) earlier impressions that the steps of the HIA process are not necessarily discrete and linear were not supported by the documentation.

The interim impact evaluation aimed to determine if the proposed project outputs matched actual outputs. Project team members from Greater Southern Area Health Service and Palerang Council reviewed the document analysis and discussed the outputs. Proposed outputs of the project were that the HIA would: (i) be used in the development of a single Local Environmental Plan, Development Control Plans and Developer Contribution Plans for Palerang Council, (ii) be used in development of the Palerang Council Social Plan, and (iii) foster a new and productive relationship between Palerang Council and the Area Health Service. 
Table 1. Health-promoting elements to incorporate into the Palerang Local Environmental and Social and Community Plans

\begin{tabular}{|c|c|c|}
\hline Physical activity & Water & Neighbourliness \\
\hline $\begin{array}{l}\text { - Mixed land use } \\
\text { - High housing density } \\
\text { - Existence of footpaths, } \\
\text { cycle ways and facilities } \\
\text { for physical activity } \\
\text { - High street connectivity } \\
\text { - Attractive and safe } \\
\text { street design } \\
\text { - Transport infrastructure } \\
\text { and systems to link } \\
\text { residential,commercial, } \\
\text { business other destinations }\end{array}$ & $\begin{array}{l}\text { - Quantity of water available for residential, } \\
\text { recreational and commercial uses } \\
\text { - Quality of water (fluoridation) } \\
\text { s }\end{array}$ & $\begin{array}{l}\text { - Opportunities for incidental contact } \\
\text { - Proactive conflict management } \\
\text { - Increased participation in decision-making } \\
\text { - Developing local identity } \\
\text { - Supporting community groups / volunteering } \\
\text { - Cultural and personal diversity } \\
\text { - Civic spaces, local businesses and local employment }\end{array}$ \\
\hline
\end{tabular}

\section{Results}

Interim results show a match between proposed and actual outputs. Nine broad recommendations covering the identified health-promoting elements can be recognised in the Bungendore Discussion Paper July 2006, the preliminary document leading to the new Palerang Local Environmental Plan and accompanying Development Control and Developer Contribution Plans. Key recommendations were also incorporated into the draft Palerang Social and Community Development Plan 2006/07-2010/11.

Project team members commented that the HIA teamwork approach reinforced the value of cross-discipline planning and brought new knowledge, tools and skills to both organisations. The benefits of using the HIA methodology were noted and include: use of additional health-related evidence to support planning decisions verified by local consultation processes, a structured opportunity to consult with subject experts and the provision of additional tools to support decision-making.

Experience from Bungendore suggests that use of HIA can assist in inserting health-related concepts into broader planning processes.

\section{References}

1. Wilkinson R, Marmot M. Social determinants of health: the solid facts. 2nd ed. Copenhagen: World Health Organization, 2003.
2. Barton $\mathrm{H}$, Mitcham $\mathrm{C}$, Tsourou C. Healthy urban planning in practice: experience of European cities. Copenhagen: World Health Organization, 2003.

3. Greater Southern Area Health Service. Bungendore health impact assessment: progress report on outcomes, 2007.

4. University of NSW Research Centre for Primary Health Care \& Equity. NSW health impact assessment project phase 3. Sydney: CHETRE and NSW Health. Available at http://www.hiaconnect.edu.au/nsw_hia_project.htm, accessed 12 December 2006.

5. Palerang Council, Greater Southern Area Health Service and Centre for Health Equity Training, Research and Evaluation. Bungendore health impact assessment: a rapid HIA of two development scenarios in Bungendore, NSW, 2006.

6. Simpson S. An introduction to health impact assessment. $N S$ W Public Health Bull 2005; 16(7-8): 106-7.

7. Greater Southern Area Health Service. Bungendore health impact assessment: progress report on outcomes, 2007.

8. Taylor L, Gowman N, Quigley R. Evaluating health impact assessment. Health Development Agency, 2003. Available at www.hda.nhs.uk, accessed 12 December 2006.

9. Quigley R, Taylor L. Evaluation as a key part of health impact assessment: the English experience. Bull World Health Organ 2003; 81: 6 .

10. Quigley R, Taylor L. Evaluating health impact assessment. Public Health 2004; 118: 544-52. doi:10.1016/j.puhe.2003.10.012

11. European policy health impact assessment - a guide. Available from http://ihia.org.uk/document/ephia.pdf. 